Tohoku J. Exp. Med., 2006, 208, 163-167

Case Report

\title{
Serum Cardiac Troponin T in Cardiac Amyloidosis: Serial Observations in Five Patients
}

\author{
Takao Kato, Yukihito Sato, Kazuya Nagao, Takahiro Horie, \\ KaZUaki Kataoka, Tadashi Miyamoto and YoshiKi TaKatsu \\ Department of Cardiovascular Medicine, Hyogo Prefectural Amagasaki \\ Hospital, Hyogo, Japan
}

\begin{abstract}
Kato, T., Sato, Y., Nagao, K., Horie, T., Kataoka, K., Miyamoto, T. and Takatsu, Y. Serum Cardiac Troponin T in Cardiac Amyloidosis: Serial Observations in Five Patients. Tohoku J. Exp. Med., 2006, 208 (2), 163-167 — The most common cause of death of patients suffering from amyloidosis is heart failure and sudden death, and cardiac troponin $\mathrm{T}$ (cTnT), a highly specific and sensitive biomarker of myocardial injury, has been reported to be a prognostic marker at presentation. But the relationship between serial measurements of serum cTnT and clinical course of the disease has not been described. An illustrative case was a 55-year-old man with normal renal function presenting with congestive heart failure $(\mathrm{CHF})$, whose initial concentration of cTnT was $0.72 \mathrm{ng} / \mathrm{ml}$. Eight samples of initial endomyocardial biopsy specimens showed the presence of myocyte degeneration and interstitial fibrosis with a small amount of amyloid infiltration. However, the cTnT values remained at $0.69 \mathrm{ng} / \mathrm{ml}$ after successful management of CHF, and four months later, a second endomyocardial biopsy revealed diffuse massive amyloid protein deposition. He died of CHF, 9 months after initial presentation. In addition, we present 4 cases of amyloidosis with increased serum cTnT levels. We therefore propose that serial measurements of serum cTnT might be helpful for early diagnosis and prediction of prognosis of patients with amyloidosis. —— troponin; cardiac amyloidosis; dilated cardiomyopathy; cardiac prognosis

(C) 2006 Tohoku University Medical Press
\end{abstract}

Cardiac troponin $\mathrm{T}$ (cTnT) is a highly specific and sensitive marker of myocyte injury in acute coronary syndromes, which has contributed to the formulation of a new definition of acute myocardial infarction (Alpert et al. 2000; Yamamoto et al. 2004) and in other situations (Apak et al. 2005). We have found that patients with dilated cardiomyopathy not due to ischemic disease who had a particularly poor prognosis had increased serum concentrations of cTnT, and that an increase in cTnT seems to indicate ongoing myocardial injury, including compensated congestive heart failure (CHF) (Sato et al. 2001, 2004; Taniguchi et al. 2004). To illustrate the potential clinical and prognostic contributions of serial measurements of cTnT in patients with cardiac amyloidosis, we present our observations in 5 patients, with special focus on a patient with amyloidosis and dilated heart, in whom the only pertinent initial laboratory abnormality was an

Received August 31, 2005; revision accepted for publication November 15, 2005.

Correspondence: Yukihito Sato, M.D., Department of Cardiovascular Medicine, Hyogo Prefectural Amagasaki

Hospital, Higashidaimotsu-cho 1-1-1, Amagasaki, Hyogo 660-0828, Japan.

e-mail: cardioys@kuhp.kyoto-u.ac.jp 
abnormally high cTnT serum concentration.

\section{Case Reports}

Case 1

A 55-year-old man was admitted to our hospital with a 5-month history of progressive dyspnea. On admission, his blood pressure was $112 / 68 \mathrm{mmHg}$, resting heart rate $70 \mathrm{bpm}$, and the remainder of his physical examination was normal. The chest roentgenogram showed a cardio-thoracic ratio of $60 \%$, and the electrocardiogram showed left axis deviation and an intraventricular conduction delay with a QRS duration of $128 \mathrm{msec}$ (Fig. 1). Echocardiography showed a dilated left ventricle, a 12-mm septal thickness (Fig. 2A). The laboratory examination on admission to the hospital showed mild hypercholesterolemia, a serum creatinine of $0.8 \mathrm{mg} / 100 \mathrm{ml}$, no proteinuria, and an unremarkable serum protein electrophoresis. Serum creatinine kinase was 141 IU/L (normal: < $160 \mathrm{IU} / \mathrm{L}$ ), and the serum cTnT concentration was $0.72 \mathrm{ng} / \mathrm{ml}$ (normal: $<0.01 \mathrm{ng} /$ $\mathrm{ml}$; Roche Diagnostics, Tokyo). Coronary angiography and left ventriculography revealed the absence of coronary artery disease, a dilated left ventricle with slightly depressed left ventricular ejection fraction (LVEF) of 58\%, and an enddiastolic volume of $191 \mathrm{ml}$. Eight samples of endo- myocardial biopsy specimens showed the presence of myocyte degeneration and interstitial fibrosis with a small amount of amyloid infiltration (Fig. 3A).

The patient was placed on a regimen of angiotensin-converting enzyme (ACE) inhibitor and diuretics, and he improved clinically. However, 4 months later, he developed edema with proteinuria at $2.7 \mathrm{~g} / \mathrm{day}$, though the serum creatinine remained at $1.3 \mathrm{mg} / 100 \mathrm{ml}$. A new electrocardiogram showed progression of the interventricular conduction delay, with a QRS duration between $160 \mathrm{msec}$ and $200 \mathrm{msec}$ on electrocardiogram (Fig. 1). An echocardiogram showed marked left ventricle hypertrophy with reduced LVEF and a septal thickness of $16 \mathrm{~mm}$ (Fig. 2B). Left ventriculography showed LVEF of 52\%. Another endomyocardial biopsy revealed diffuse massive myocardial infiltration by amyloid protein (Fig. 3B). The serum concentration of cTnT was 0.69 $\mathrm{ng} / \mathrm{ml}$ (Fig. 4). Despite continued treatment of CHF, the patient was readmitted to the hospital for management of low output syndrome with reduced LVEF on echocardiography. He died 9 months after his first evaluation. The serum cTnT concentrations, which were abnormally high at a stage of disease when renal function was normal, remained high throughout the follow-up.

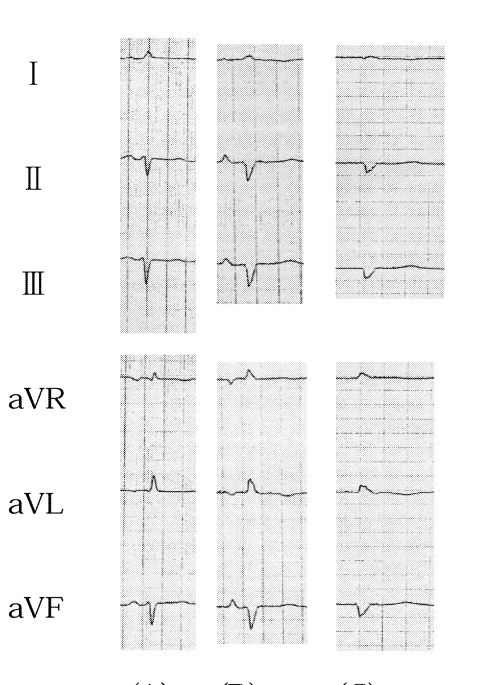

(A) $\quad$ (B) $\quad$ (C)

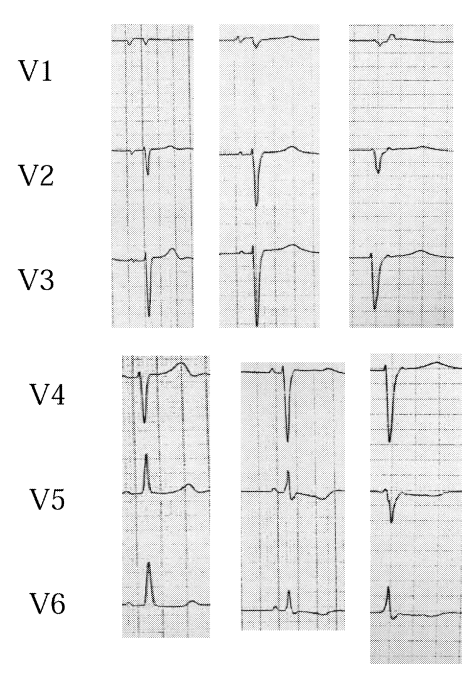

(A) $\quad$ (B) $\quad$ (C)

Fig. 1. Serial electrocardiograms recorded in Case 1.

(A) Initial recording, (B) recording at 4 months of follow-up, and (C) recording at 9 months of follow-up. 
(A)

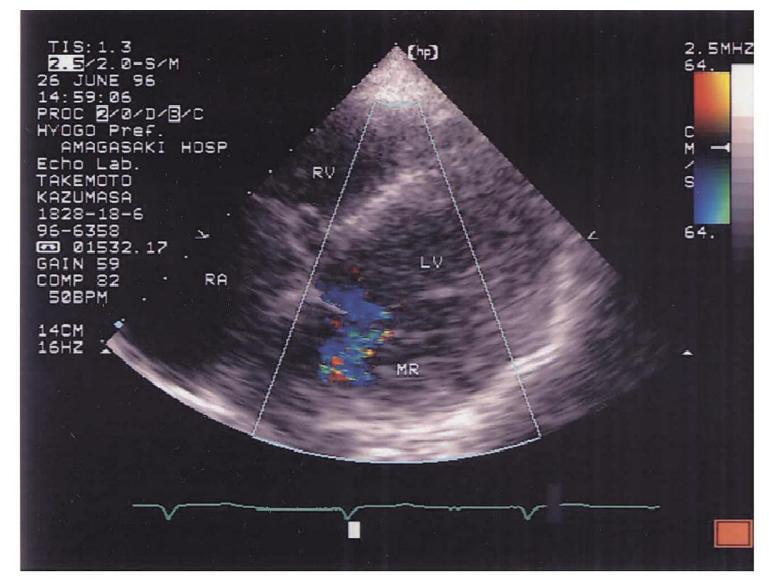

(B)

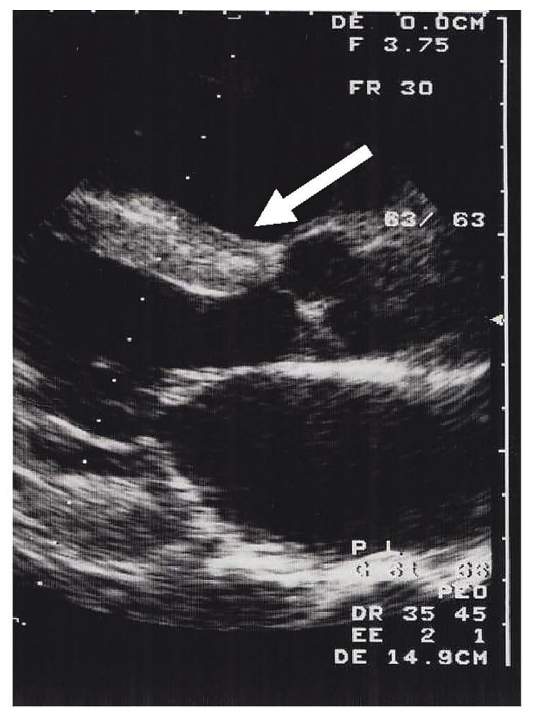

Fig. 2. Echocardiography recorded in Case 1.

(A) Initial recording showed a thickened myocardium. (B) Recording at 4 months later. A white arrow indicates the thickened septum with a granular sparkling appearance.

(A)

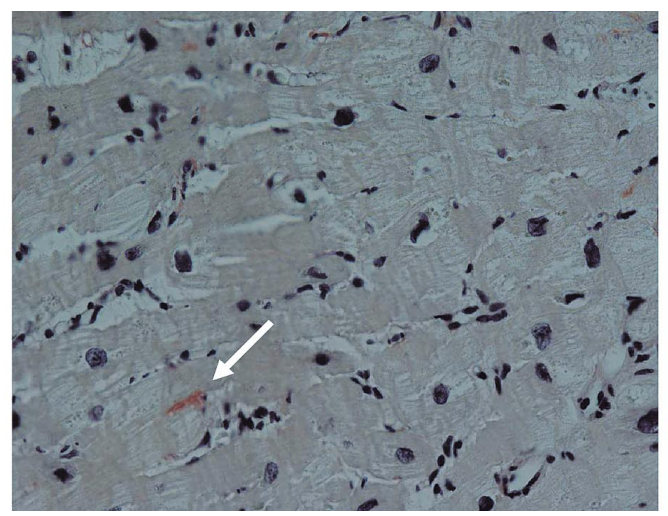

(B)

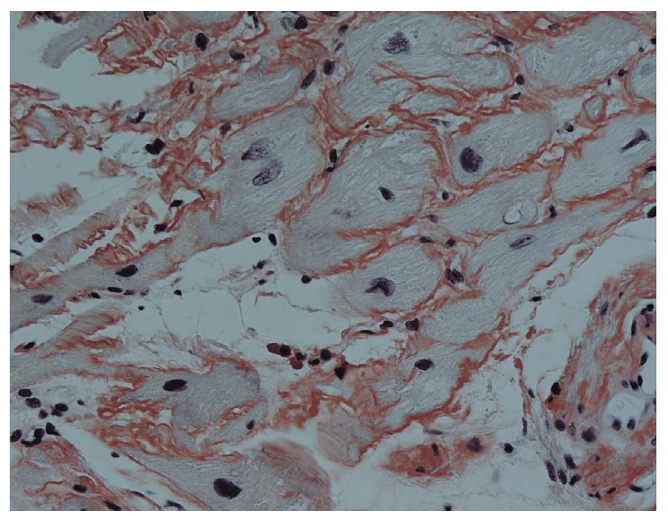

Fig. 3. Endomyocardial biopsy specimens in Case 1.

(A) Initial biopsy showed minimal amyloid infiltration stained in orange (white arrow) (Dylon stain. Original magnification $\times 400$ ). (B) Second biopsy showed massive interstitial amyloid deposition (Dylon stain. Original magnification $\times 400$ ).

\section{Case 2}

A 58-year-old man admitted to the hospital for management of CHF was treated with diuretics and an ACE inhibitor. His serum creatinine was $1.2 \mathrm{mg} / 100 \mathrm{ml}$. An endomyocardial biopsy revealed infiltration by amyloid protein and a diagnosis of cardiac amyloidosis was made. The initial serum concentration of cTnT was $0.38 \mathrm{ng} /$ ml (Fig. 4). After resolution of pulmonary congestion the serum concentrations of cTnT remained high and increased gradually to $1.04 \mathrm{ng} /$ $\mathrm{ml}$. He then developed low output syndrome and pulmonary congestion, and died 5 months after his initial presentation. 


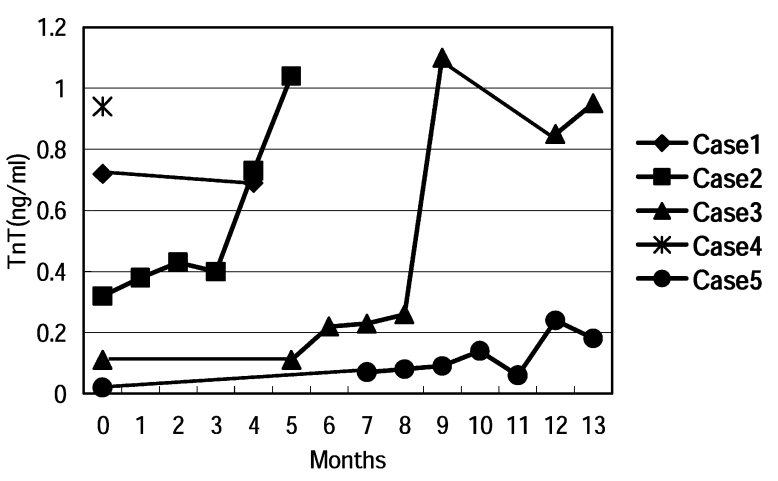

Fig. 4. Serial concentrations of cTnT measured in the 5 patients presented in this report. Patients 1 - 4 have died.

\section{Case 3}

A 68-year-old man, who had received a pacing system for sick sinus syndrome 7 months earlier, presented with dyspnea due to $\mathrm{CHF}$, and a serum creatinine of $3.2 \mathrm{mg} / 100 \mathrm{ml}$. The serum concentration of cTnT, which was $0.10 \mathrm{ng} / \mathrm{ml}$ at the time of pacemaker implantation, had increased to $0.22 \mathrm{ng} / \mathrm{ml}$. Microscopic examination of a right ventricular endomyocardial biopsy revealed the presence of infiltration by amyloid protein. The serum concentration of cTnT increased to a peak of $1.10 \mathrm{ng} / \mathrm{ml} 2$ months later (Fig. 4), when he began suffering from repetitive bouts of severe CHF. He died 4 months after the peak increase in cTnT concentration.

\section{Case 4}

A 69-year-old man without ischemic heart disease presented with sick sinus syndrome. He had primary amyloidosis diagnosed by renal biopsy performed for nephrotic syndrome 17 months earlier, when his serum creatinine was 1.9 $\mathrm{mg} / 100 \mathrm{ml}$, and had been treated with hemodialysis for the past 7 months. The serum concentration of cTnT was $0.94 \mathrm{ng} / \mathrm{ml}$ (Fig. 4). He died suddenly 1 month later of suspected ventricular tachyarrhythmia.

\section{Case 5}

A 64-year-old man with cardiomegaly, proteinuria and a serum creatinine of $1.2 \mathrm{mg} /$ $100 \mathrm{ml}$ was diagnosed with primary amyloidosis
20 months before our cardiac evaluation. The serum concentration of cTnT was $0.02 \mathrm{ng} / \mathrm{ml}$. Echocardiography showed marked hypertrophy with a septal wall thickness of $13 \mathrm{~mm}$. Global LVEF was maintained with $75 \%$ and decceceration time was $164 \mathrm{msec}$ with the pseudonormalized pattern of the transmitral flow velocity. He was placed on a regimen of melphalan and prednisone. While proteinuria and serum creatinine $(1.1 \mathrm{mg} / 100 \mathrm{ml})$ decreased, the concentrations of cTnT slowly increased over several months to 0.18 ng/ml (Fig. 4), during which his septal wall has gradually thickened to $16 \mathrm{~mm}$, with LVEF of $60 \%$.

\section{Discussion}

The most common cause of death in patients suffering from amyloidosis is cardiac, either from progressive $\mathrm{CHF}$ or sudden, due to ventricular tachyarrhythmias or asystole (Gertz et al. 2004). Multiple prognostic factors have been identified, such as diastolic dysfunction (Klein et al. 1991), decreased LVEF, and thickened ventricular wall (Swanton et al. 1997) on echocardiography, and serum $\beta$-2 microglobulin, a weaker prognostic marker (Gertz et al. 2004). In addition, Dispenzieri et al. (2003) reported that high serum concentrations of cTnT at the time of diagnosis of primary systemic amyloidosis might signal a poor prognosis. These investigators also found the combined measurements of troponins and $\mathrm{N}$-terminal pro-brain natriuretic peptide (NTproBNP) at presentation useful in the risk stratification of patients suffering from amyloidosis (Dispenzieri et al. 2004). While these 2 reports focused on cardiac biomarkers at the time of diagnosis, the relationship between serial measurements of serum cTnT and clinical course of the disease has not been described.

Serial measurements of cTnT are important because of two points. First, increased concentrations in cardiac amyloidosis might be a reliable sign of cardiac injury due to infiltration by amyloid protein and might predict impending disease progression and adverse cardiac events. Second, they may allow the detection of cardiac involvement at an earlier stage when the microscopic 
examination of endomyocardial tissue does show minimal infiltration by amyloid protein, and when monoclonal (M)-protein is not detectable in urine or blood.

All our patients had concentrations of cTnT that were markedly higher than in patients with dilated cardiomyopathy (DCM) and ongoing myocardial injury (Sato et al. 2001). The 4 nonsurvivors had concentrations at presentation between $0.11 \mathrm{ng} / \mathrm{ml}$ and $0.94 \mathrm{ng} / \mathrm{ml}$. One patient died suddenly after 1 month later, while the other 3 had persistently or increasingly high concentrations of cTnT despite successful management of $\mathrm{CHF}$, before dying of uncontrollable cardiac decompensation or low output syndrome. This indicates the possibility that, despite the compensated cardiac state, myocardial injury was progressing, due to persistent infiltration by amyloid protein. The high heart specificity and sensitivity of its measurements seem to confer cTnT an advantage in the early detection of cardiac involvement. In our first patient, the serum concentration of cTnT was elevated and also had electrocardiographic evidence of myocardial disease, with widening of the QRS complex on electrocardiogram at when no M-protein was found in the urine or blood, and before microscopic examination of the endomyocardium showed the presence of diffuse amyloid protein deposition. However, the possibility of sampling errors of initial endomyocardial biopsy has not been excluded.

The concentrations of cTnT in the last surviving case remains relatively low compared with those of non-survivors, because of the effective chemotherapy or other unknown reasons. However, his slowly increased cTnT level needs close observation of progression of the cardiac involvement. The efficacy of chemotherapy for primary cardiac amyloidosis might be monitored by serial measurements of cTnT, though this needs further studies.
In conclusion, in patients with amyloidosis, serial measurements of serum cTnT might be helpful to monitor patients as well as clinical signs and laboratory findings, such as electrocardiography and echocardiography.

\section{References}

Alpert, J.S., Thygesen, K., Antman, E. \& Bassand, J.P. (2000) Myocardial infarction redefined--a consensus document of the Joint European Society of Cardiology/American College of Cardiology Committee for the redefinition of myocardial infarction. J. Am. Coll. Cardiol., 36, 959-969.

Apak, I., Iltumur, K., Tamam, Y. \& Kaya, N. (2005) Serum cardiac troponin $\mathrm{T}$ levels as an indicator of myocardial injury in ischemic and hemorrhagic stroke patients. Tohoku J. Exp. Med., 205, 93-101.

Dispenzieri, A., Kyle, R.A., Gertz, M.A., Therneau, T.M., Miller, W.L. \& Chandrasekaran, K. (2003) Survival in patients with primary systemic amyloidosis and raised serum cardiac troponins. Lancet, 361, 1187-1189.

Dispenzieri, A., Gertz, M.A., Kyle, R.A., Lacy, M.Q., Burritt, M.F. \& Therneau, T.M. (2004) Serum cardiac troponins and $\mathrm{N}$-terminal pro-brain natriuretic peptide: a staging system for primary systemic amyloidosis. J. Clin. Oncol., 22, 3751-3757.

Gertz, M.A., Merlini, G. \& Treon, S.P. (2004) Amyloidosis and Waldenstrom's macroglobulinemia. Hematology (Am. Soc. Hematol. Educ. Program.), 257-282.

Klein, A.L., Hatle, L.K., Taliercio, C.P., Oh, J.K., Kyle, R.A. \& Gertz, M.A. (1991) Prognostic significance of Doppler measures of diastolic function in cardiac amyloidosis. A Doppler echocardiography study. Circulation, 83, 808-816.

Sato, Y., Yamada, T., Taniguchi, R., Nagai, K., Makiyama, T., Okada, H. \& Takatsu, Y. (2001) Persistently increased serum concentrations of cardiac troponin $\mathrm{T}$ in patients with idiopathic dilated cardiomyopathy are predictive of adverse outcomes. Circulation, 103, 369-374.

Sato, Y., Kita, T., Takatsu, Y. \& Kimura, T. (2004) Biochemical markers of myocyte injury in heart failure. Heart, 90, 1110-1113.

Swanton, R.H., Brooksby, I.A., Davies, M.J., Coltart, D.J., Jenkins, B.S. \& Webb-Peploe, M.M. (1977) Systolic and diastolic ventricular function in cardiac amyloidosis. Studies in six cases diagnosed with endomyocardial biopsy. Am. J. Cardiol., 39, 658-664.

Taniguchi, R., Sato, Y. \& Kita, T. (2004) Combined measurement of cardiac troponin $\mathrm{T}$ and $\mathrm{N}$-terminal pro-brain natriuretic peptide in patients with heart failure. Circ. J., 68, 1160-1164.

Yamamoto, M., Komiyama, N., Koizumi, T., Nameki, M., Yamamoto, Y. \& Toyoda, T. (2004) Usefulness of rapid quantitative measurement of myoglobin and troponin $\mathrm{T}$ in early diagnosis of acute myocardial infarction. Circ. J., 68 , 639-644. 